\title{
LVIII. Action of free molecules on radiant heat, and its conversion thereby into sound
}

\author{
John Tyndall F.R.S.
}

To cite this article: John Tyndall F.R.S. (1882) LVIII. Action of free molecules on radiant heat, and its conversion thereby into sound, Philosophical Magazine Series 5, 13:83, 435-462, DOI: $10.1080 / 14786448208627212$

To link to this article: http://dx.doi.org/10.1080/14786448208627212

册 Published online: 28 Apr 2009.

Submit your article to this journal $[\pi$

Џ Article views: 4

Q View related articles $\square$ 
LVIII. Action of Free Moleoules on Radiant Heat, and its Conversion thereby into Sound. By JoHn Trndali, F.R.S.*

\section{Contents.}

Sect. 1. Intron Page

1. Partial Sion $\ldots \ldots \ldots \ldots \ldots \ldots \ldots \ldots \ldots \ldots \ldots, 435$

2. Partial Summary of previous Work . . . . . . . 430

3. Researches of Magnus . ................... 446

4. Experiments resumed: Verifications ............. 450

\section{\$1. Tntroduction.}

THE experimental researches of Rumford and Leslie raised 1 the subject of Radiant Heat to an extraordinary pitch of interest and importance. Both of these philosophers occupied themselves with what may be called superficial emission and absorption.

Melloni is to be regarded as the founder of our knowledge of the transmission of radiant heat through solids and liquids. Save in a passing inference, to be noticed immediately, Melloni left untouched the gaseous form of matter-thinking, probably, that gases and vapours, though their diathermancy could hardly be supposed theoretically perfect, came in this respect so near perfection as to be placed beyond the grasp of laboratory experiment. It was doubtless the general prevalence of this conviction which caused this field of inquiry to lie fallow for so many years after the discovery of the thermo-electric pile.

By an experimental arrangement characteristic of the genius of the man, though, it may be, not quite equal to the requirements of the problem, Melloni proved that the law of inverse squares held good for radiant heat in air; and from this he inferred the absence of all sensible absorption, by air, within the distance embraced by his experiments $\uparrow$. Melloni extended to radiation his conclusion regarding absorption. "On ne connaitt" he writes, "aucun fait qui démontre directement le pouvoir émissif des fluides élastiques purs et transparents" $\ddagger$. Such was Melloni's relation to the subject now before us.

* Communicated by the Author, having been read before the Royal Society, January 23, 1882. The substance of this paper was delivered orally as the Bakerian Lecture on November 24, 1881.

$\dagger$ "Pour un intervalle de cinq à six mètres, l'air n'exerce aucune absorption sensible pour le rayonnement des corps chauds." L La Thermochrose, p. 136.

I Annales de Chimie et de Physique, vol. xxii. p. 494. 
In 1855 Dr. Franz, of Berlin, published a paper "On the Diathermancy of certain Gases and Coloured Liquids"*. He found that air contained in tubes 452 and 900 millimetres long, absorbed 3.54 of the radiation from an Argand lamp; and he concluded that all transparent gases would behave like air. I have given reasons for holding that Dr. Franz in these experiments did not touch the question in hand $\dagger$. In the arrangement which he describes, the absorption by air was quite insensible. But 60 per cent. of the radiation from his powerful source was lodged in the glass ends of his tubes; these, as secondary sources, radiated directly and indirectly against his pile; and it was their chilling by the cold air that slightly lowered his deflection and produced the supposed absorption.

It is not improbable that other attempts were made to bring gaseous matier under the dominion of experiment; but none to my knowledge are recorded.

\section{\$2. Partial Summary of previous Work.}

My researches on magne-crystallic action carried with them the incessant use of conceptions and reasonings touching molecular constitution and arrangement. At an early period of these studies it occurred to me that heat, both in its radiant and in its ordinary thermometric form, might be turned to good account as an explorer of molecular condition. The first fruit of this idea was a paper "On Molecular Influences" $\ddagger$, in which it was shown that wood possesses three axes of calorific conduction coincident with the axes of elasticity discovered by Savart. Experiments on certain crystals recorded in this paper suggested a possible connexion between diathermancy and conductivity; and in 1853 I worked at this question. The substances then submitted to experiment were rock-crystal, amethyst, topaz, beryl, rocksalt, 'smoky quartz, fluor spar, tourmaline, Iceland spar, dichroite, arragonite, heavy spar, flint, and glass of various kinds. These ninerals were employed in the shape of cubes carefully cut and polished, the transmission through each of them, in different directions, both of radiant and conducted heat being determined.

A desire for completeness, not then attained, caused me to postpone, and finally to forego the publication of the results

* Poggrendortt's Annalen, vol. xciv. p. 337.

+ Philosophical Transactions, 1861, vol, cli, p. 27, and elsewhere.

$\neq$ Ibid, 1853, vol, cxliii. p. 217. 
of this inquiry. It, however, kept alive reflections on the influence of molecular constitution on the phenomena of radiation and absorption. Encountered continually by the thought that in liquids and solids the pure molecular action was, or might be, hampered by cohesion, the desire to bring, if possible, free molecules under the dominion of experiment beset me more and more.

At the beginning of 1859 I definitely attacked this problem, meeting at the outset difficulties and negations the reverse of encouraging. But after some weelss of labour, I found myself in secure possession of the result, that gases and vapours exhibited, in relation to radiant heat, phenomena far more surprising than those observed by Melloni in liquids and solids. On the 26th of May, 1859, the subject was brought before the Royal Society *; and on the 10th of June I was able, by illuminating the dial of a galvanometer and casting its image upon a screen, to demonstrate in the Royal Institution not only the fact of absorption, but the astonishing differences of absorption which gases and vapours equally transparent to light manifested in regard to radiant heat + .

The following gases and vapours were then examined:Air, oxygen, hydrogen, nitrogen, carbonic oxide, carbonic acid, nitrous oxide, coal-gas, ammonia, olefiant gas, bisulphide of carbon, chloroform, benzol, iodide of ethyl, cyanide of ethyl, formate of ethyl, acetate of ethyl, propionate of ethyl, iodide of amyl, chloride of amyl, amylene, absolute alcohol, amylic alcohol, methylic alcohol, ethylic ether, ethylamylic ether, sulphuric ether, and some others. In the Philosophical Magazine for $1862 \mathrm{I}$ have given samples of the results obtained with a few of these substances; and I will here confine myself to the remark that were the measurements there recorded multiplied a hundredfold, they would fall far short of the number actually executed in $185 \%$.

With the view of compelling the feeblest gases and rapours to show, if they possessed it, their capacity to absorb radiant beat, the "method of compensation "was invented $\ddagger$. Without prejudice to the delicacy of the galvanometer, this method enabled me to bring into play quantities of heat far greater than those ever previously invoked, my object being so to exalt the total radiation that a minute fraction of that total should reveal itself to experiment. By this method not only were the feebler gases and rapours coerced, but the rastness of the diathermic range, if I may use the phrase, was esta-

* Proceedings of Royal Society, vol. x. p. 37 .

$\dagger$ Proceedings of Royal Institution, rol. iii. p. 155.

$\ddagger$ Philosophical Transactions, 1861 , rol cli. pp. $6 \&$ \& 
blished with a clearness and an evidence unattainable by any other means then existent *.

Notices of the investigation having appeared in many English and continental journals $\dagger$, I was induced to defer the detailed publication of the experiments. The investigation itself had taught me the difficulties and dangers which beset it. These had reference both to the methods of experiment and to the purity of the substances employed. To secure the perfect constancy of the sources of heat, and the perfect steadiness of the galvanometer, when the flux of heat was powerful, involved a lengthened discipline. With neither gases nor vapours, moreover, was it easy to obtain uniform results. When generated in different ways, the action of the same gas would sometimes prove itself so discordant as to suggest to me the possible existence of novel allotropic conditions to account for such variations of behaviour. Two samples, moreover, of nominally the same liquid, would furnish rapours yielding results far too divergent to be tolerated. The drying apparatus also contributed its quota of disturbance. These anomalies were finally traced to the fact that an incredibly small amount of impurity, derived from the stronger gases or vapours, sufficed to disguise and falsify the action of the weaker ones. All this had to be learnt; and when learnt, I thought it desirable, for the sake of accuracy, not to publish the results which had been gained with so much labour, but to go once more, with improved appliances, over the same ground. This I did, though it involved the total abandonment of seven weeks' uninterrupted experimental work in 1859 , of seven weeks' similar work in 1860 , and of many fragmentary efforts. On the 10th of January, 1861, the memoir containing an account of the investigation was handed in to the Royal Society $¥$.

* With moderate total heats the method of compensation is extremely easy of application; but when the total radiation is very large, some discipline is required to keep the galvanometer-needle steady in its most sensitive position. With due training, however, perfect mastery over this difficulty may be obtained.

$\dagger$ Proceeding's of the Royal Society, May 26, 1859; Proceeding's of the Royal Institution, June 10, 1859 ; Bibliothèque Universelle, July 1859 ; Cosmos, vol. xv. p. 321 ; Nuovo Cimento, vol. x. p. 196 ; Comptes Rendus, 1859 ; and in other journals.

$t$ Section 3 of the Bakerian Lecture for 1861 reveals some of the difficulties which beset the earlier stages of these inquiries. To secure strength of radiation and steadiness of the needle I passed from source to source, obtaining my temperatures in turn from water, oil, fusible metal, sheets of copper heated by regulated flames, and from other things. Approximate results were readily obtainable; but I aimed at a degree of accuracy which would render any material retractation afterwards unnecessary. Soundness of work I thought preferable to rapidity of publication. 
The first point of importance established in 1859, and developed in the memoir just mentioned, was that already referred to, namely the fact of absorption and large differences of absorption. The second point-destined, I think, to throw light on the deeper problems of molecular physics, was the proof, that while elementary gases offered a scarcely sensible impediment to radiant heat, equally transparent compound gases exhibited, in many cases, an energy of absorption comparable to that of the most athermanous solids and liquids. Determining, for example, the action of a mechanical mixture of two elementary gases, it was proved that without altering either the quantity of matter, or its perfect transparency to light, the absorption of invisible heat might be increased many hundredfold by the passage of the constituents of the mixture into a state of chemical combination.

A similar deportment may be detected in liquids and solids. The quantity of iodine vapour generated at ordinary temperatures is so small that its action on radiant heat is, as might be expected, insensible. But iodine itself, when liquefied by a powerful solvent, behaves as an almost perfectly transparent body to the obscure calorific rays, even when it is able to extinguish totally the light of the sun. Liquid bromine is also highly diathermanous. The same may be said of phosphorus. In Melloni's table Sicilian sulphur comes next to rock-salt in transmissive power. A concentrated solution of sulphur in bisulphide of carbon exerts no sensible action on radiant heat. By fusing together iodine and sulphur Professor Dewar has produced a "ray-filter" which separates with extreme sharpness the visible from the invisible rays. The remarkable diathermancy of certain specimens of vulcanite, brought to light in the experiments of Mr. Graham Bell and Mr. Preece, is probably due to the sulphur they contain. Melloni showed that lampblack is to some extent diathermanons. But when a suitable source of heat is chosen, lampblack proves far more pervious to radiant heat than Melloni found it to be. An opaque layer of this substance transmits 41 per cent. of the radiation from a hydrogen-flame. Were the lampblack optically continuous, the transmission would, doubtless, be still greater. An opaque solution of iodine transmits 99 per cent. of the radiation from the same source; while a layer of pure water, 0.07 of an inch in thickness, transmits only 2 per cent. of the radiation from a hydrogenflame. Such results indicate that a profound change in the relation of ponderable matter to the luminiferous ether accompanies the act of chemical combination.

One of my principal aims in the Bakerian Lecture of 1861 
was to illustrate the hold which experiment had obtained of a subject previously considered intractable. The densities of the gases and vapours employed were therefore varied within wide limits. In the experimental tube first made use of, a full atmosphere of olefiant gas absorbed more than 80 per cent. of the entire radiation; and it was therefore evident that a small fraction of an atmosphere of such gas would exert a measurable action. On trial, it was found possible to measure the absorption of $\frac{1}{10,000}$ of an atmosphere of olefiant gas. The action of this gas was determined at sixteen different densities, the absorption, as long as the density was rery small, being accurately proportional to the quantity of gas present. Similar experiments were made, and similar results obtained with other gases. The action of sulphuric ether vapour upon radiant heat was proved to be still more powerful than that of olefiant gas. The vapour was first carried into the experimental tube by a current of dry air; and the pure vapour was afterwards examined at seventeen different densities. Bisulphide of carbon was tested at twenty different densities, amylene at ten, benzol at twenty, and so of the others.

Considering the viows previously entertained regarding the diathermancy of gases and vapours, I was naturally impressed with these results. Sceptical when I first observed them, I scrutinized them closely, until repeated scrutiny abolished every doubt. For my own instruction I illustrated the action of the stronger gases and vapours in a variety of ways. Turning, for example, once rapidly round a cock connecting the exhausted experimental tube with a holder containing a powerful gas, the needle would fly aside, owing to the stoppage of the heat by the infinitesimal amount of gas which entered the tube during the rotation. Discharging a powerful gas or vapour in free air, between the source of heat and the thermopile, a similar energetic action would be produced by the perfectly invisible agent.

I was schooled in such actions before the thought of testing the omnipresent vapour of our atmosphere occurred to me. When it did ocenr, there was in my mind no it priori ground for supposing that its action would prove insensible; for why should I assume that $\frac{1}{100}$ of an atmosphere of aqueous vapour would prove neutral, after I had proved a small fraction of this fraction, on the part of other gases and vapours, to be active? There was no reason for such an assumption on $\mathrm{my}$ part-nothing to deter me from hopefully submitting the question to experiment. I accordingly tested the water rapour of the atmosphere in which I worked, and found its 
action on a first trial to be thirteen times that of the air in which it was diffused.

It is not uninstructive to compare this approach to the problem with that of a very distinguished man-the late Professor Magnus, of Berlin*. Subsequent to me, he subjected the aqueous vapour of our atmosphere to an experimental test; but he made the experiment under the assured conviction that his result would be negative. "It could," he says, "be foreseen with certainty that the small amount of aqueous vapour taken up by air at ordinary temperatures could exert no influence on the transmission." I think it must be obvious that if Magnus had gone through the discipline to which I had been subjected, he would not have used this language. His mistake, however, was a natural one. In fact during the earlier stages of the inquiry my mind was exactly in the condition of his mind-I also thinking, until practically instructed to the contrary, that the action of aqueons vapour at ordinary temperatures must be immeasurably small. It is well known that Magnus tested his foregone conclusion, and found it rerified; while I, on the other hand, as abore stated, justified mine.

The various gases which had been examined in the experimental tube with regard to their powers of absorption, were next tested as regards their powers of radiation. Columns of the heated gases were allowed to ascend in free air, and to radiate against the pile. In this simple way the radiative power of "transparent elastic fluids" was for the first time established. The order in which the gases ranged themselves, in regard to radiation, was exactly the order of their absorptions. Here, as in other cases, I instructed myself by observing how gases might be made to play the part of solids. Permitting, for example, a film of one of the stronger gases to glide over a heated surface of polished silver, the radiation from that surface was augmented as it might have been by a coating of isinglass or lampblack.

A surmise has been mentioned regarding new allotropic conditions, as occurring to me anid the perplexities of my earlier experiments. In one instance, that of electrolytic oxygen, the surmise proved correct. My first experiments indicated that the modicum of ozone which went forward with the oxygen exerted four times the absorption of the gas in which it was diffused + . Subsequently, by changing the apparatus, and taking pains to atignent the quantity of ozone,

* In unany respects my generous and helpful friend; but, in regard to this question, my steadfast antagonist for many years.

$\dagger$ Plilosophical Transactions, rol. cli. p. 8. 
the multiple rose successively from 4 to $20,35,47,85$, ascending finally to $136^{*}$. The behaviour of ozone was thus proved to be similar to that of molecules composed of heterogeneous atoms. Hence the conclusion, drawn at the time, that the molecule of ozone was formed of oxygen atoms so grouped as to render their action upon radiant heat virtually that of a compound body. This, it is needless to say, is the constitution now assigned to ozone.

With the view of including corrosive gases and vapours among the number of those examined, and for other reasons, the brass experimental tube was displaced by a tube of glass of the same diameter and nearly 3 feet long. The source of heat was also changed from a Leslie's cube containing boiling water, to a plate of copper against which a sheet of flame was permitted to play. Extraordinary precautions were found necossary to ensure perfect steadiness on the part of the flame. With this arrangement the practical inability of the elementary gases to absorb radiant heat was further illustrated and confirmed. Chlorine gas and bromine vapour, for example, were proved to be highly diathermanous.

At the pressure of an atmosphere it was found that the diathermic range of colourless gases extended from 1 to about 1000. The portion of gas first entering the experimental tube, having the whole heat to act upon, produced, as might be expected, the greatest effect, the increment of absorption (after a certain quantity of gas or rapour had entered) being: infinitesimal $\dagger$. It was therefore interesting to compare together the various gases at very small pressures. When the pressure was that of 1 inch of mercury the diathermic range was greatly increased, the absorption by olefiant gas being then at least 6000 times the absorption by atmospheric air.

With the changed apparatus the action of the aqueous

* Philosophical Transactions, vol. clii. pp. 84, 85 .

$\uparrow$ This is well illustrated by an experiment on sulphuric ether vapour recorded in the Bakerian Lecture for 1861:-

$\begin{array}{cc}\text { Pressure. } & \text { Absorption. } \\ 1 \text { inch. } & 214 \\ 2 \text { inches. } & 282 \\ 3 \quad " & 315 \\ 4 \quad " & 330 \\ 5 \quad " & 330\end{array}$

The absorption of air being taken as unity, that of sulphuric ether vapour at 1 inch mercury pressure is here shown to be 214 . When, however, rapour corresponding to a pressure of 4 inches was already in the experimental tube, the addition of another inch did not sensibly alugment the absorption. 
vapour of our atmosphere was again taken up, and proved to be, not 13 times, as I had at first supposed, but, on fairly hmmid clays, at least 60 times that of the air in which it was diffused. When carefully dried air was caused to pass over moistened glass, and then carried into the experimental tube, the absorption was still greater.

A power has been claimed for mist or haze which has been denied to aqueous vapour; but in these experiments concentrated luminous beams, which would have infallibly brought into view the least trace of suspended matter, revealed no mist or dimness of any kind. It is, moreover, demonstrable that an anount of turbidity, rendered strikingly ovident by it luminous beam, exerts only a fractional part of the action of the pure aqueous vapour. When well-dried air was led, not through water or over wet glass, but over bibulous paper, taken apparently dry from the drawers of the laboratory, the amount of vapour carried forward from the pores of the papes: produced 72 times the absorption of the air which carried it. After five repetitions of the experiment, wherein the same air was carried over the same paper, a quantity of vapour was still sent forward capable of exerting 47 times the absorption of the air in which it was diffused.

Here the possible action of odour's upon radiant heat naturally suggested itself. Many perfumes were accordingly subjected to cxamination, the odorous substance being in each ease carried into the experimental tube by a current of dry air. Thus tested, pachouli exerted 30 times, cassio 109 times, while aniseed exerted 372 times the absorption exerted by the air in which it was diffused.

A novel method of exhibiting the absorption and radiation of gaseous bodies, the germ of which had been previously discovered *, was illustrated and dereloped by the new apparatus. Suppose the experimental tube exhausted, and the needle, under the joint action of the two sources, to be at $0^{\circ}$. On admitting a strong vapour the usual deflection would occur. Suppose it to be 50 galvanometric degrees. Let dry air be now introduced until the experimental tube is filled. Althongh fresh matter is thus thrown athwart the rays of heat, the needle behaves as if the matter within the cxperimental tube had wholly disappeared. It sinks to zero, and not only so, but passes, say to $50^{\circ}$, on the other side.

After the first moments of perplexity succeding the observation of this effect, its canse became clear. On entering the experimental tube the air, having its vis vira destroyed, was

* Philosophical transactions, vol, cli. p. 3:2. 


\section{Prof. Tyndall on the Action of Tree Molecules on}

heated dynamically. Incompetent to radiate itself, it imparted its warmth to the vapour, and this powerful radiator poured the heat thus received against the pile. This heat sufficed not only to neutralize the deflection of $50^{\circ}$ due to absorption, and indicating cold, but to carry the needle up to $50^{\circ}$ on the side of heat. So likewise, when the experimental tube was filled with mixed air and vapour, the needle being at $0^{\circ}$, a stroke of the pump, though opening a freer passage for the rays from the source, caused a deflection indicative not of heat, but of cold. Here, the vapour within the tube, being chilled by the dilatation of the air, the pile radiated its uncompensated warmth into the vapour and produced the observed deflection.

Such observations suggested a new means of demionstrating the absorption and radiation of heat by gases and vapours. Abandoning all external sources of heat, and permitting the various gases already examined to enter the experimental tube at a common velocity, they became self-heated and radiated against the pile. Their radiation, thus determined, corresponded exactly with the results obtained when heated columns of these gases were permitted to rise freely in the atmosphere.

Both the radiation and absorption of vapours were determined in the same manner. The external source of heat was abandoned, and a measured quantity of every vapour was introduced into the experimental tabe. Through an orifice of fixed dimensions dry air was then permitted to enter the tube, where the destruction of its vis viva raised its temperature. The heated air warmed the vapour, which in its turn radiated the heat imparted to it against the pile. The deflection of the galvanometer declared the strength of this radiation. Absorption was determined by permitting the mixed air and vapour to dilate by a measured quantity, the pile being here the warm body, and the chilled vapour the absorbent. The order in which the vapours stood as regards absorption was here exactly the order of their radiation; while both absorption and radiation, thus determined, agreed with the results obtained by sending the rays from an external source of heat through the pure vapours in the experimental tube.

What has been called "vapour-hesion," whereby liquid films are produced, has been supposed to play a dominant part in my experiments. But it can hardly be imagined that an irregular action of this kind could produce results of such precision and consistency as those here recorded. Such results are, in my opinion, only compatible with the con- 
clusion that the veritable radiators and absorbers are the molecules of the vapours. Apart from all experiment, the notion that vapours must act in this way comes commended to us by the proved, and conceded, deportment of gases. It would be unreasonable to admit that a compound gaseous molecule is active, and at the same time to affirm that a compound vaporous molecule is inert.

This hypothesis of liquid films formed on the interior surface of the experimental tube, and on the plates of rock-salt, becomes, I think, more embarrassed as we proceed. It depends on the unproved assumption that liquids possess powers of absorption which are denied to their vapours. To water and brine, for instance, Magnus largely concedes such powers, but not to aqueous vapour. That the state of aggregation exerts an influence is not denied; but that it is here the dominant factor is open to doubt. To admit this would be to concede that the seat of absorption is the molecule as a whole, to the prictical exclusion of the constituent atoms of the molecule. For if the atoms exert any influence, the mere passage from the liquid to the vaporous condition, which separates the molecules from each other, but leares them individually intact, cannot destroy their powers of absorption.

At an early stage of these researches the parallelism of liquid and vaporous absorption forced itself upon my attention. Thus my experiments on bisulphide-of-carbon vapour were connected with the deportment of liquid bisulphide, as set forth in Melloni's table. The vapours, moreover, of chloride of sulphur and chloride of phosphorus, whose liquids stand in Melloni's table next to bisulphide of carbon, were afterwards proved by me to possess a diathermancy corresponding to that of their liquids. After various references to this subject in preceding memoirs, a portion of the Bakerian Lecture for 1864 was devoted to its examination. Liquid layers enclosed between plates of transparent rock-salt were tested in regard to their diathermancy; and, for the sake of control and verification, they were employed in five different thicknesses. The vapours of these liquids were examined in quantities proportional to the quantity of liquid, the same quality of heat being applied both to liquids and vapours. By these experiments it seemed to me placed beyond a doubt that the liberation of the molecule from the liquid condition did not destroy its absorbent power, the order of absorption being proved to be precisely the same for liquids and their vapours. Ten different substances were shown at the time here referred to to follow this rule. The list has since been extended; and I am not acquainted with a single real exception to the rule. Phil. Mag. S. 5. Vol. 13. No. 83. June 1882. $2 \mathrm{~L}$ 
Any reasoning, therefore, which ascribes a potent absorption to perfectly impalpable films, condensed on the surface of my apparatus, and which denies that absorption to the free molecules within the experimental tube, is in my opinion untenable.

The relation between liquids and their vapours here indicated is very thorough. It extends beyond the field of experiment which we have hitherto had in view. I have, for example, published some researches on the action of rays of high refrangibility on gaseous matter, and have shown, in a great variety of cases, that the molecules are shaken asunder by such rays. The actinic clouds, as I have called them, produced by this decomposition reveal vividly the track of the beam by which they are generated, and render it easy to observe the distance to which the action penetrates. In the case of nitrite of amyl; for example, the power of decomposition is soon exhausted, the actinic cloud ceasing abruptly at a point about 18 inches from the place where the beam eniers the vapour. An experimental tube 3 feet long has therefore one half of its vapour shielded by the other half; and on reversing the tube, the shielded balf comes instantly down as an actinic cloud. In the case of iodide-of-allyl vapour, on the other hand, the beam may pass through a charged experimental tube 5 feet long, fill it with an actinic cloud, and still effect decomposition in another tube placed beyond it. What is true of these vapours is true equally of their liquids; for while a layer of the liquid nitrite $\frac{1}{8}$ of an inch thick prevents, when placed in the track of the beam, the decomposition of its vapour, a layer of the liquid iodide, of quadruple thickness, does not arrest the decomposition. The power, and the lack of power, to be penetrated to considerable depths is shared alike by the liquids and their vapours. Other, and still more subtle and penetrating illustrations of parallelism between liquid and vaporous absorption are mentioned in the Bakerian Lecture for $1864^{*}$

\section{§. Researches of Magnus.}

Prompted by the experiment of Grove, illustrating the chilling action of hydrogen, Magnus, in 1860, began an in-

* Carbonic acid is one of the feeblest of the compound gases, as regards the radiation from solid bodies; but for the radiation from a carbonic oxide flame it transcends all other gases in absorbent power. The action of aqueous vapour is also enhanced when it acts upon the rays emitted by a hydrogen-flame. The enhancement extends to water. Curious reversals of diathermic position, when heat from different sources is employed, are moreover shown to occur simultaneously with liquids and vapours. 
vestigation on the power of gases to conduct heat*. His apparatus, traced in outline from his own plate, is shown in fig. 1, where A B is the recipient for the gases, and $\mathrm{C}$ a flask containing water kept boiling by a current of steam. The bottom of $\mathrm{C}$, which formed the top of $A B$, was the source of heat. A thermometer, $g f$, shielded by a cork or metal screen $o o^{\prime}$ from the radiation of the source, was intended to receive and measure the heat transmitted by conduction. The recipient A B was mounted in a space surrounded by water of a constant temperature. The heating of the thermometer when A B was exhausted $\dagger$, was compared with its heating when A B was filled with various gases; and in every case but one the heating through the gas was Fig. 1.

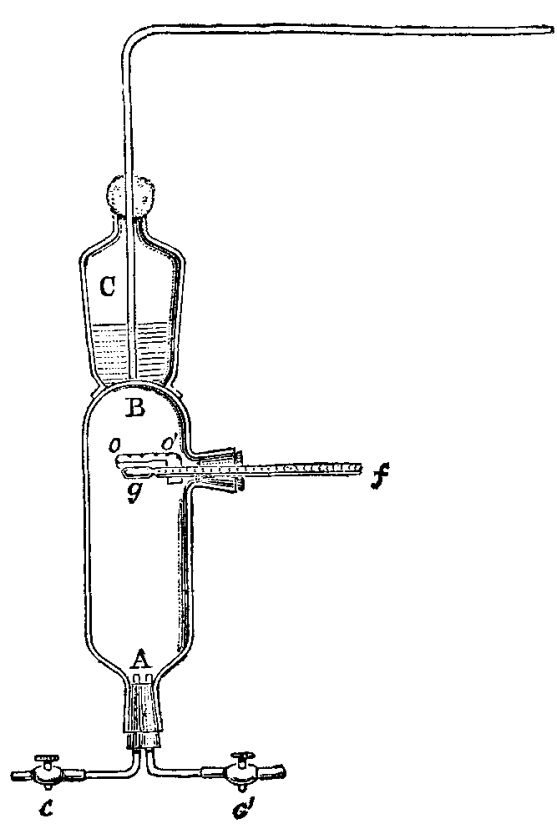
found less than the heating through the vacuum. The exception was hydrogen, which carried more heat to the thermometer than was transmitted by the vacuum. The conclusion drawn by its author from this experiment was that hydrogen conducted heat like a metal.

One remark only in this Note has any reference to the diathermancy of gases; but it is a significant one. Magnus had no doubt as to the power of every one of his gases to conduct heat. There could, he supposed, be only a difference of degree between them and hydrogen. Whence, then, the

* A Preliminary Note of this inquiry is published in the Bericht of the Berlin Academy for July 30, 1860. No measurements are given; but certain results are announced. The experiments were first published in Poggendorff's Annalen for April 1861.

+ This vacuum-temperature, at least in so far as it exceeded that of the sides of the recipient, was obviously derived from the screen. 
lowering of the thermometer? He answers thus:-" From this it is not to be inferred that the gases do not conduct heat, but merely that in their case conduction is so feeble as to be neutralized by adiathermancy." These are the only words in the note which have any reference to radiation.

In his next inquiry Magnus dealt directly with the subject of diathermancy, a Preliminary Note of "the investigation being published in the Monatsbericht for February 7 th, 1861. This note, like its predecessor, consisted of general and descriptive statements, no actual measurements being given. The completed memoir was first published in Poggendorff's Annalen for April 1861. For the purposes of this new inquiry the apparatus used in the experiments on gaseous conduction was modified, as shown in fig. 2. To the recipient A B a second one $G \mathrm{~F}$ was attached, the two being connected by the tubulure shown in the figure. The recipient $G F$ rested upon the plate of an air-pump, on which also stood the thermopile $p$, with one of its faces turned towards the source. From the pile, through the air-pump plate, wires passed to the galvanometer. With this apparatus, the absorption by atmospheric air and by oxygen was found to be $11 \cdot 12$, and by hydrogen 14.1 per cent. of the total radiation. The alleged conductivity of hydrogen did not therefore mannifest itself in these experiments.

Let us analyze these results. In the first experiments the distance of the thermometer from the source of heat was 35 millimetres. The action on the thermometer through a vacuum being represented by 100 , the action through air and through oxygen of this depth was found to be 82 . The loss of 18 per cent. in air and in oxygen was alleged to be due to the adiathermancy of these media; to which percentage, if we wish to ascertain the total absorption by air, we should have to add such heat as reached the thermometer by conduction.

Turning now to the modified apparatus, which is evidently drawn to scale, the gas here traversed by the radiant heat was about 275 millimetres in depth, while the stratum traversed in the first experiments was, as stated, only 35 millimetres. Yet in these first experiments an absorption of 18 per cent., while in the later ones an absorption of only $11 \cdot 21$ per cent., is assigned to air. In other words, when the depth of the aerial stratum was augmented more than sevenfold, the absorption, instead of increasing, fell to less than two thirds of that of the shallower stratum. It is pretty obvious that an influence different from pure absorption came here into play. That influence was convection.

Anxious to probe this matter to the bottom, and to abolish, 
Radiant Heat, and its Conversion thereby into Sound. 449 or account for, the differences between my friend and myself, I wrote to him proposing an exchange of apparatus-that he should send his to London, and I mine to Berlin. I afterwards had a facsimile of his apparatus constructed in London,

Fig. 2.

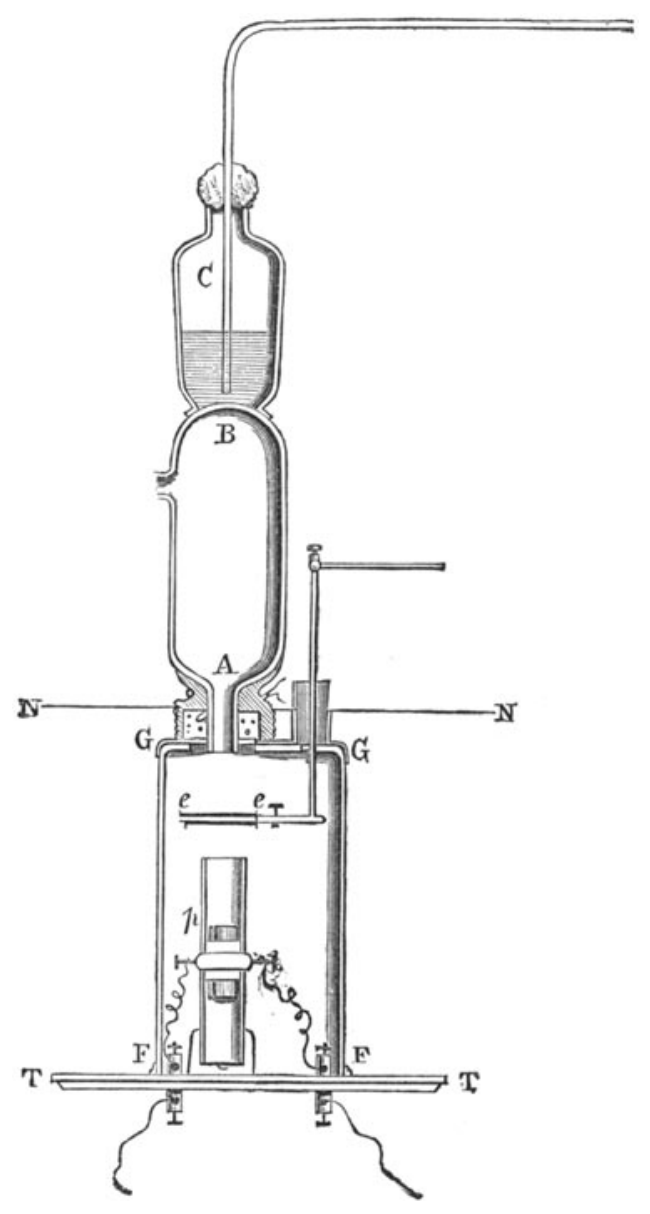

and satisfied myself by actual trial that it was really hampered with the defects I had ascribed to it. By means of the striæ of incense smoke and of chloride of ammonium, the fact of convection in air was rendered plainly visible to the eye ; while the behaviour of hydrogen, under like circumstances, 
revealed the cause of its transporting more heat than the vacuum in the first experiments, and less heat, not only than the vacuum, but than air or oxygen, in the second experiments. In the one case the thermometer, being close to the source, came within the range of the convection-currents of this mobile gas, the heat being transported to it by these currents. In the other case a considerable distance intervened between the source and the pile, which was further effectually protected by the narrow tubulure. Through it the currents could not pass; but they nevertheless existed in the recipient $\mathrm{A} \mathrm{B}$, lowering the temperature of the source without heating the thermoscopic instrument.

The experimental resources of Magnus were great, and he here applied them; but the defects of his method were radical and irremovable. These defects reached their culmination in the subsequent researches of Professor Buff*, who, by pursuing substantially the same method, arrived at the result that a stratum of air $2 \frac{1}{2}$ inches thick absorbed 60 per cent. of the radiation from a source of $100^{\circ}$ C. $\dagger$ Buff also found olefiant gas to be more diathermanous than air; whereas at atmospheric pressures it is many hundred, and at a pressure of $\frac{1}{30}$ of an atmosphere many thousand times more opaque to heat.

This is the point at which aqueous vapour enters into the experiments of Magnus. When dry and humid air were compared together in his apparatus, no difference between them was observed. But, apart from all disturbanee, it would require an instrumental arrangement far more delicate and powerful than that here employed, to bring into view the action of a stratum of mixed air and aqueous vapour 11 inches deep, and having a temperature of only $15^{\circ} \mathrm{C}$. Disturbances, however, were not absent. In the first place, the convection currents which enabled dry air to reduce the radiation by 11.12 per cent., were more than sufficient to mask the action of the vapour. Secondly, dry and humid air were brought in succession into direct contact with the face of the thermopile. The pile was therefore affected by any difference of temperature between it and the air, and it could scarcely be supposed that these temperatures were always alike. It was also affected by the condensation and evaporation which occurred when humid air and dry air were brought successively into contact with its lampblack-coated face. To "yapour-hesion" Magnus subsequently ascribed very large effects. Here we have the conditions specially suited to the development of the

* Phil. Mag. 5th ser. vol. iv. p. 401. For my reply see Proc. Roy. Soc. vol. $\mathrm{xxx}$. p. 10.

$\dagger$ Ibid. 1877, vol. iv. p. 424. 
action, and yet no reference is made to it. Either, then, the disturbance was overlooked, or the apparatus was not sufficiently delicate to reveal it. To these two sources of disturbance (the lowering of the temperature of the source by convection, and the warming and chilling of the pile by contact, condensation, and evaporation) is to be added another, due to the warming which must have occurred when the dynamically heated air came into direct contact with the thermopile - an action which, in my apparatus, proved sufficient to whirl the needle of the galvanometer more than once through an entire circle.

Magnus next experimented with glass tubes 1 metre long and closed at the ends with plates of glass. His source of heat was a strong gas-flame aided, as in the experiments of Dr. Franz, by a parabolic mirror. Two tubes were employed, the one blackened within, and the other unblackened. With the blackened tube an absorption of 2.44 per cent. was found for air, and an absorption of 3.75 per cent. for hydrogen. In the unblackened tube the absorption by air was 14.75 per cent., and by hydrogen 16.27 per cent. of the total radiation.

I went over this ground with the utmost care, using invisible as well as visible heat. But, substituting plates of pellucid rock-salt for the plates of glass, I failed to realize the effect obtained by Magnus. He ascribed the difference between the results obtained with his blackened and his unblackened tube to a change of quality in the heat, produced by reflection from the interior surface of the latter. With plates of rock-salt, however, though the reflection abides, the change of quality does not occur. My position, therefore, in regard to these experiments is similar to what it was in regard to those of Dr. Franz. The results obtained with air, oxygen, and hydrogen were, I hold, due to the chilling of the heated glass ends of the tube by the cold gases, and the consequent lowering of the secondary radiation.

It was shown by Magnus himself, and is moreover obvious at first sight, that the unblackened tube sent a far greater amount of heat to the glass plate adjacent to the thermopile than the blackened one. That plate being more heated by the source, was more chilled by the air when it entered. The greater cooling-power of hydrogen accounts, moreover, for the advance of the supposed absorption from $14 \cdot 75$ to $16 \cdot 27$ per cent. With carbonic acid Magnus detected a difference which had escaped Dr. Franz. Instead of making the action of this gas equal to that of air, he found in the blackened tube an absorption of 8.19 per cent., and in the unblackened tube an absorption of 21.92 per cent., exerted by carbonic acid. 
Here true absorption mixed itself with the effect of mere chilling, while with still more powerful gases the effect of chilling retreated by comparison more and more.

Such were the experiments which determined, in the first instance, the attitude of this distinguished man towards that portion of my work which related to the action of the air and vapour of our atmosphere on radiant heat. In the defence of his position he brought to bear all the resources of consummate skill and large experience. His position, however, was by no means a wholly defensive one. He dwelt repeatedly and emphatically on the dangers-and they are realto which the method pursued by me was exposed. I had closed my experimental tube with plates of transparent rocksalt; and he urged against me the hygroscopic character of this substance. Placing rock-salt beside a vessel of water under a glass shade, he found that it could be rendered dripping wet*. Hence his argument that, instead of measuring the action of vapour, I had really measured the action of brine. This, however, I could not admit. I was aware of the danger, and had avoided it. In many hundred instances the rock-salt plates had been detached from my experimental tube while filled with the very air which had produced the observed absorption, and found to be as dry as polished plate-glass. For a week at a time I have charged my experimental tube alternately with dried and undried air, removing every evening the plates of salt while the humid air filled the tube. Their dryness and polish were found unimpaired + . I have frequently flooded the experimental tube with light, and watched narrowly whether any dimness showed itself on the salt, or on the interior surface, when the humid air entered. There was nothing of the kind. I finally abandoned the plates of salt altogether, and obtained in a tube opened at both ends substantially the same effects as those obtained when the tube was closed with plates of rock-salt.

In 1862 Magnus came to London. He had been previously working at the points of difference between us, and lad strengthened his first conviction. The action of the air he had found to be considerable, and the action of aqueous vapour practically nil. I also had been working, but with an entirely

* It has been shown by Professor Dewar that the exposure of a dry plate of rock-salt for five minutes to saturated air sensibly augments the weight of the salt as determined by a delicate balance.

$\uparrow$ This mastery over the apparatus was not attained without training. Any lapse of care soon declared itself by the condition of the plates of salt. 
different result. It was hoped by both of us that our differences would be settled during this visit. With my closed experimental tube I showed him the neutrality of dry air and the activity of humid air; and while the latter was in the tube I detached the rock-salt plates and placed them in his hand. He clusely inspected them, passed his dry handkerchief over them, and frankly and emphatically pronounced them perfectly dry. I then executed in his presence the experinents with the open tube, and reproduced the results which I had previously published. I subjected the method of compensation to a severe test, and showed him how exact it could be made. He frankly confessed his inability to find any flaw in my experiments, and, save in one particular, made no attempt to reconcile our differences. He accounted for the neutrality of dry air observed by me by pointing to my thermopile, between which and the experimental tube a space of air intervened. He argued, and justly argued, that though the calorific rays were permitted to enter the tube from a vacuum, if the air intervening between tube and pile could produce the effect which he ascribed to it, the heat would be robbed of its absorbable rays before the dry air entered the tube, the subsequent nentrality of dry air being a matter of conrse. The logic was good; but its basis I knew to be more than doubtful; and I therefore asked him whether a layer $\frac{1}{20}$ of an inch thick between pile and tube would produce any sensible effect. His reply was an emphatic negative. In subsequent experiments, therefore, the conical reflector was removed from my pile, and placed within the experimental tube, its narrow end being caused to abut against the plate of rock-salt. The face of the pile was then brought within less than ${ }_{20}^{1}$ of an inch of the rock-salt plate; and in this way my former measurements, which had declared the pure air of our atmosphere to be a practical vacuum to radiant heat, were verified to the letter.

The well-earned fame of Magnus as an experimenter, and his personal friendliness to myself, rendered it specially incumbent on me to deal respectfully with every one of his suggestions. He once intimated to me that the absorption, which I had supposed due to aqueous vapour, might be really due to the smoke and dust suspended in London air. To meet this I carried air myself from the Isle of Wight, had it carried from Epsom Downs and other places, and found the aqueous vapour diffused in such air to be from 60 to 70 times more energetic than the air itself. London air, moreover, was freed from its suspended matter, and tested when dry : it proved neutral. The self-same air was then rendered humid: 
its absorbent power was restored. Then, with dry air as a carrier, I introduced smoke into the experimental tube, until it far exceeded in density that suspended in the Londun air when Magnus drew my attention to it. The quantity of heat intercepted by this smoke proved to be only a fraction of that absorbed by the perfectly invisible aqueous vapour.

On his return to Berlin he resumed his labours. He had been especially impressed by the experiments with the open tube; and to this point he directed his chief attention. "The result of this experiment," he writes, "was so surprising, and so little in accord with what I had found by other methods, that on reaching home I determined to repeat the experiment." He did so, with this result:- "I have," he says, "repeated the blowing-in of dry air and moist air many hundred times; but in no single case was the deflection such as to indicate a greater absorption by moist air" *. Humid air, in his experiments, produced the deflection of heat; dry air the deflection of cold-a result diametrically opposed to mine. In London he had seen that my deflections were as large as I had affirmed them to be; but he had not criticised them with the view of ascertaining whether they were, or were not, in the right direction. In these new experiments, however, he had, he thought, hit upon their origin. The moving air had reached the face of the thermopile, producing, when humid, heat by condensation, and, when dry, cold by evaporation.

I read the account of these experiments with some concern; for it was thereby made plain to me that Magnus had by no means realized the anxious care that I had bestowed upon my work. The testimony of an independent observer would, I thought, set the matter right. My apparatus, carefully adjusted, was accordingly handed over to Dr. Frankland, who minutely tested every point involved in, or arising out of, the objection of Magnus. He verified all my results. His opinion as to the accuracy of the method of compensation is worth recording. "In conclusion," he writes, "I cannot but express my surprise and admiration at the precision and sharpness of the indications of your apparatus. Without having actually worked with it, I should not have thought it possible to obtain these qualities in so high a degree in determinations of such extreme delicacy" + . To this may be

* Poggendorff's Annalen, 1863, vol. cxviii. p. 580; Phil. Mag. 1863, vol. $x \times$ vi. p. 25.

+ The total heat here employed amounted to $86^{\circ} \cdot 2$ of a quadrant. This exceedingly large deflection was neutralized by the radiation from the compensating cube. But so accurately were the two sources balanced, and so constant was the radiation on both sides, that the determinations were made with ease, and without sensible disturbance or fluctuation. 
added the subsequent testimony of Professor Wild, now of the University of St. Petersburg, who went carefully over the same ground. "In all my experiments," he says, "conducted according to Tyndall's method, which included more than a hundred distinct observations, I have never obtained deflections of the galvanometer-needle in contradiction to the statements of Professor Tyndall "* *

In an extremely able paper, a translation of which is published in the Philosophical Magazine for October 1866, the Petersburg philosopher compares the methods pursued by Magnus and myself respectively. Insufficient sensitiveness, and the disturbance due to convection-currents, cansed him, he says, to abandon the method of Magnus. "Although," he continues, "this method of investigating absorption may, in the hands of so experienced and expert an experimenter as Professor Magnus, be an appropriate one for determining absolute values with great certainty, I feel bound, from my own experience, to give a decided preference to Tyndall's method, not only on account of the greater facility with which it furnishes qualitative [quantitative] results, but also in consequence of its greater delicacy. It is principally in consequence of this greater delicacy that, notwithstanding the negative results furnished by Magnus's method, I maintain that the greater absorptive power of moist air, as compared with dry, has been fully established by the experiments made according to Tyndall's method; and I am of opinion that meteorologists may without hesitation accept this new fact in their endeavours to explain phenomena which hitherto have remained more or less enigmatical."

In 1866 Magnus varied his method of experiment, seeking to solve the question of absorption by observations on radiation. "I have," he says, "made a few determinations of the radiation of dry and moist air, and of some other gases and vapours. Up to the present time," he continues, "the capacity of these bodies to transmit heat has alone been determined" $\dagger$. He then describes his arrangement :- "The gases and vapours were passed through a brass tube of 15 millimetres internal diameter, which was placed horizontally and heated by gas-flames. One end of the tube was bent upwards, so that the heated air ascended vertically, while at a distance of 400 millimetres from the vertical current was placed the thermopile." When dry air was sent through this tube, the deflection produced was three divisions of a scale; when air which had passed through water at a

* Phil. Mag. 4th ser. vol. xxxii. p. 252.

+ This is an inadvertence. Exhaustive experiments on the radiation of gases and rapours had been made and published many years previously 
temperature of $15^{\circ} \mathrm{C}$. was sent through the tube, the deflection rose to fire divisions; when the water was warmed to $60^{\circ}$ or $80^{\circ}$ Fahr., the deflection was 20 divisions; and when the water boiled, the deflection was 100 divisions. In this last experiment, however, a mist appeared; so that, as urged at the time, the radiation could not be said to have been purely from vapour. In the other cases no mist was visible; but it was nevertheless concluded that the 20-division deflection was due to the formation of mist at the boundary of the ascending current.

I should be disposed to claim these experiments as telling in my favour. The first of them, in my opinion, dealt with the radiation, not from dry air, but from the adjacent aqueous vapour which had been warmed by the dry air. That the deflection in the second experiment was small is not surprising. The radiation which could reach the pile from a jet of air only 15 millimetres in diameter, and containing such moisture as could be taken up at $15^{\circ} \mathrm{C}$., must have been extremely small under any circumstances. But in the present case, even this small radiation was diminished by the passage of the heat through 400 millimetres of undried air. I should demur to the explanation of the third experiment, and question the warrant to imagine a mist which could not be seen. Even the fourth experiment, where mist was visible, yielded, I doubt not, a mixed result- - part of the effect, and probably the smallest part, being due to the mist, and part of it to the vapour.

With regard to the radiation from hot aqueous vapour, the following experiment is typical of some hundreds which I have had occasion to make. A burner, cunsisting of two rings provided with numerous small apertures, was placed within a square tin chimney. At some height above the burner the chimney was perforated, so as to enable the radiation from a heated gaseous column within the chimney to reach a distant thermopile. The side of the chimney facing the pile was so protected by screens that the radiation from the chimney itself was nil. Connecting the burner with a bottle of compressed hydrogen, the gas was ignited. A column of hot vapour rose from the burner and passed the aperture in the chimney through which it sent its rays to the pile. Mere tips of flame were first employed, the column of vapour rising from them sufficing nevertheless to produce a permanent deflection of

$$
40^{\circ} .
$$

A slight augmentation of the flame sent the needle up to $60^{\circ}$. 
A still further augmentation sent it up to

$75^{\circ}$.

This last deflection was equivalent to more than 400 of the degrees in the neighbourhood of zero.

The radiating column was here considerably above the flame. To examine the condition of the column, a concentrated luminous beam was directed upon it. There was no precipitation. On the contrary, the suspended matter in the air of the chimney was much less than that of the surrounding air. Instead of a white mist, we had the blackness due to the destruction of the floating matter by the hydrogen-flame.

On quenching the flame, the needle returned accurately to zero.

In his objections Magnus, for the most part, dealt with true causes; but he erred as to their scope of action. I never denied the existence of the dangers which he emphasized. The bygroscopic character of rock-salt, for example, to which he recurred so often, cannot be questioned. It has a strong attraction for moisture, especially when cold. On this point my experience has been large; and I applied it in the execution of my experiments. These, as I have so frequently stated, were conducted with plates of salt as dry as polished glass or rock-crystal. Thus, while conceding the fact that rock-salt is hygroscopic, I demur to its application.

$\AA$ similar remark applies to the last solution offered by Magnus of the differences between us. In 1867 he showed that vapours were condensed by surface-attraction to a greater extent than had previously been supposed. Blowing vapourladen air into a metal tube, he found that heat was generated. He inferred, and rightly inferred, that this heat was produced by the condensation which occurred on the interior surface. This condensation he found to depend on the condition of the surface, being greater when it was tarnished or coated than when it was polished. He saturated air with moisture at a temperature of $16^{\circ} \mathrm{C}$, and then raised both it and his pile to a temperature of $38^{\circ}$. When such air was blown against the dry face of the pile, heat was generated. Condensation therefore occurred upon a surface $22^{\circ} \mathrm{C}$. higher than the dew-point of the vapour. Against this I have nothing to urge. But the fact by no means justifies the inference drawn from it, which was, that the rapours in my experimental tube were converted by "vapour-hesion" into liquid layers of high opacity to radiant heat; these layers, acting upon the calorific rays impinging on the interior surface of my tube, produced the absorption which I had erroneously ascribed to the 
vapours. More than this, the liquid layers were supposed to be broken up into discontinuous patches, which not only absorbed the heat but scattered it. "Vapour-hesion," it may be added, was found to vary with the liquid which produced the vapour, being particularly strong in the case of alcohol.

Magnus brought this generalization to the test of experiment, but failed to verify it. He urged humid air against a dry mirror, from which radiant heat was reflected; but unless he wetted the mirror visibly, no effect was produced on the reflected beam. Still he held that reflection, oft repeated, rendered sensible an action which eluded a single reflection. My position here is clear. I do not doubt surface attraction, or deny the existence of impalpable films. No experiment was ever made on the reflection of light or radiant heat in which such films did not intervene; but they had as little effect upon my results as they had upon those of De la Provostaye and Desains*, and of other refined experimenters. As early as $1859 \mathrm{I}$ was made aware of the danger which might arise from condensation. Warned by the action of chlorine on my brass experimental tube, I coated it inside with lampblack, and retested with it all my vapours. The result removed from my mind the suspicion that surface condensation had any thing to do with the observed absorption. Many similar experiments with blackened tubes were subsequently made by me, for my own safety and instruction. There was no substantial difference between the results obtained with such tubes and those obtained with polished tubes in which internal reflection came into play.

Such are the general features and phases of a discussion which, though dealing only with a small item of my work, has consumed a considerable amount of time. Other able experimenters have entered this field, the latest of whom, MM. Lecher and Pernter, have published a long and learned memoir in Wiedemann's Annalen, which has been translated in the Philosophical Magazine for January 1881. My experiments with gases they corroborate, but not those with vapours. Regarding the action of aqueous vapour they are especially emphatic, their conclusion being "that moist air does not perceptibly absorb the heat-rays from a source of $100^{\circ} \mathrm{C} . "$ In fact, they found moist air a little more transpa-

* Considering the energy of water as a radiator, exceeding, according to Leslie, that of lampblack itself, the film of this liquid which must have covered the plates of silver in the experiments of the two French philosophers ought, if Magnus be correct, to have sensibly raised the emission. Calling the emission from lampblack 100, that from polished silver plus the film was only $2 \cdot 1$. 
rent than a vacuum. "No imaginable source of error," they affirm, "has here been left out of account." The arrangement for filling with moist air was varied, the air allowed to stand for a long time over the water in the gas-holder, and this moist air then passed through several wash-bottles into the experimental space, but with the same negative result. In common with Magnus, MM. Lecher and Pernter ascribe my results to the condensation of liquid films on the rock-salt plates, and on the polished inner surface of my tube*

\section{\$4. Experiments resumed: Verifications.}

With a view to my own instruction and to the removal of uncertainty from other minds, these researches on radiant heat were resumed in November 1880. A brass experimental tube 4 feet long, $2 \frac{3}{8}$ inches in diameter, and polished within, was first employed ${ }^{\dagger}$. Interposed between it and the source was a "front chamber," through which, when exhausted, the rays passed into the experimental tube. A plate of transparent rock-salt separated the tube from the chamber, while a second plate of salt closed the distant end of the experimental tube. The source of heat was at first a Leslie's cube containing water at $100^{\circ} \mathrm{C}$., to one of the faces of which the end of the front chamber was carefully soldered. The chamber also passed air-tight through a copper cell in which a continuous circulation of cold water was kept up. The heat which might otherwise have reached the experimental tube by conduction from the source was thus cut off. One face of a thermopile, provided with a reflecting cone, received the rays which passed through the experimental tube. The other face, also provided with a cone, received the rays from a "compensating cube," used, as formerly, to neutralize the radiation from the source, and to bring the needle of the galvanometer to zero when the experimental tube was exhausted. On the entrance, then, of

* However I may otherwise differ from MM. Lecher and Pernter, I agree with their opening remark, that few other questions of experimental physics present difficulties so great as the one here under consideration. Nor do I see reason to differ from their closing words, that " the extraordinary difficulty of investigations of this sort would be richly repaid by the attainment of quantitative results; whilst the corresponding optical investigations (immeasurably easier) will always remain more of a qualitative nature." It is the difficulty here signalized that has caused so many distinguished investigators to go astray in this field of inquiry. I may state here that on the receipt of their paper I wrote to MM. Lecher and Pernter, but my communication was returned from Vienna through the dead-letter office.

$\dagger$ The plate answering to this description will be found in the Philosophical Transactions for 1861. 
any absorbent gas or vapour the equilibrium was destroyed, the needle moved from zero; and from the observed permanent deflection the absorption was calculated. Other qualities of heat, and other experimental tubes than that here described, were afterwards introduced into the inquiry.

I here give the measurements executed in 1880 with the vapours of nine different liquids, in experimental tubes of the dimensions above given.

\section{TABLe I.}

\begin{tabular}{|c|c|c|}
\hline & $\mathrm{Va}$ & urs. \\
\hline Press & $\begin{array}{l}\text { Leslie's } \\
\text { cube, } \\
\text { vacuum }\end{array}$ & $\begin{array}{c}\text { Leslie's } \\
\text { cube } \\
\text { free. }\end{array}$ \\
\hline
\end{tabular}

Bisulphide of carbon . 48 in. mer. $4 \cdot 4 \quad 5 \cdot 0 \quad 7 \cdot 6$

Chloroform . . . . . $.36 \quad, \quad 12 \cdot 8 \quad 12.9 \quad 28 \cdot 8$

Benzol . . . . . . $32 \quad \% \quad 14.8 \quad 15 \cdot 0 \quad 44.5$

Iodide of ethyl . . . $\begin{array}{lllll}36 & \prime & 18 \cdot 4 & 19 \cdot 3 & 47 \cdot 0\end{array}$

Iodide of methyl . . $\cdot 46 \quad \% \quad 25 \cdot 0 \quad 26 \cdot 2 \quad 59 \cdot 0$

Amylene . . . . . $\cdot 26 \quad " \quad 26 \cdot 1 \quad 27 \cdot 2 \quad 65 \cdot 0$

Sulphuric ether . . . $28 \quad " \quad 35 \cdot 0 \quad 35 \cdot 6 \quad 71 \cdot 0$

Acetic ether . . . . $\cdot 29 \quad, \quad 43 \cdot 3 \quad 43 \cdot 7 \quad 77 \cdot 5$

Formic ether . . . .36 ” $43 \cdot 3 \quad 44 \cdot 0 \quad 78 \cdot 0$

The "pressures" in this table are chosen with a view to the comparison of liquids and vapours. They express quantities of vapour which are proportional to the quantities of matter in the respective liquids at a common thickness. The two next columns contain the absorptions per 100 of the heat from two Leslie's cubes, the one with a vacuum in front of it, the other placed in free air and well protected from air-currents. The close agreement of the two columns proves the "front chamber" to be a superfluity. It also illustrates the coincidence to be attained in these measurements when they are carefully made. In the last column I have placed the absorptions exerted by liquid layers of the respective substances at a common thickness of one millimetre. The source of heat here was an incandescent platinum spiral. The order of absorption of liquids and vapours is the same.

This order is, as might be expected, undisturbed when we apply heat of the same quality to liquids and vapours respectively. This is shown by the following table:- 
TABLE II.

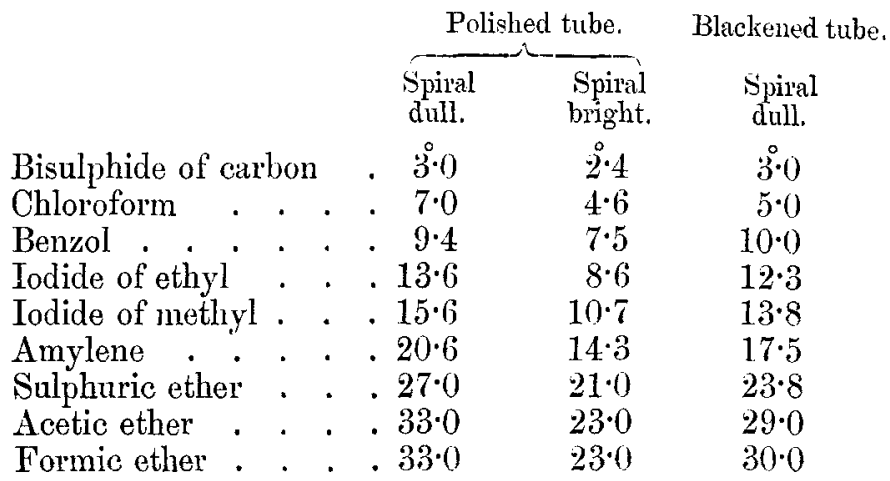

The vapour-pressures here are the same as those employed in Table I. The order of absorption is the same in both tables; but its amount is diminished. This was to be expected, from the difference in the quality of the heat. We are dealing with transparent vapoturs-in ofher words, vapours pervious to the luminous rays; and the greater the proportion of these rays in the calorific beam, the less will be the absorption. This is well illustrated by the second column in the table, which show's the fall of the absorption when the spiral is raised from a dull red to almost a white heat. The polished tube was used in both these cases.

The third column of figures in Table II. shows the results obtained when the experimental tube was coated within with lampblack. The absorptions are in the same order, and almost of the same amount as those of the first column. The case is representative, and might be multiplied to any extent. It is incompatible with the notion that my results were due to films collected on the polished interior surface of my experimental tube.

Placing the substances recently experimented on in the order of their absorption, and also in the order which they exhibited in 1864, we have the following two columns:-

$$
1880 .
$$

Bisulphide of carbon.

Chloroform.

Benzol.

Iodide of ethyl.

Iodide of methyl.

Amylene.

Sulphuric ether.

Acetic ether.

Formic ether.
1864.

Bisulphide of carbon.

Chloroform.

Iodide of methyl.

Iodide of ethyl.

Bemzol.

Amylene.

Sulphuric ether.

Acetic ether.

Formic ether.

Phil. Mag. S. 5. Vol. 13. No. 83. June 1882. 2 M 
In 1864 , therefore, the iodide of methyl proved itself more diathermanous than the iodide of ethyl, while both of them were more diathermanous than benzol. 'In 1880 the case was precisely the reverse. Suspecting that the discrepancy might be due to impurity, I requested my friend Professor Dewar to subject the liquids to a further process of purification. Tested afterwards, they produced the following deflections:-

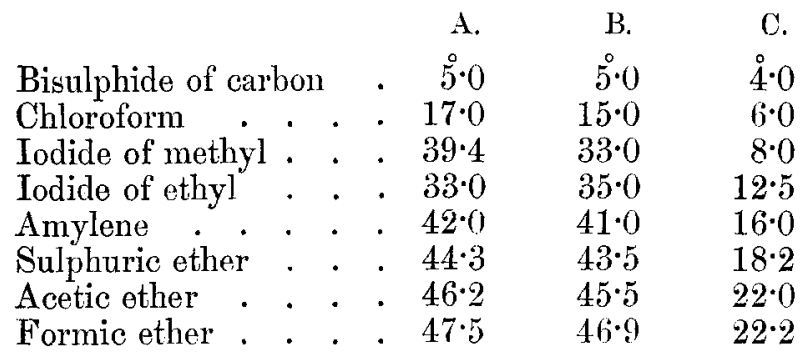

Under A and B respectively are the deflections prodnced by the liguids prior to and after purification. The iodide of methyl falls from $39^{\circ} 4$ to $33^{\circ}$, while the iodide of ethyl rises from $33^{\circ}$ to $35^{\circ}$. The relative positions occupied by the liquids in 1864 are thus restored. Benzol, however, remained permanently lower than before. Under C are the deflections produced by the vapours of the purified liquids. Here also the positions of the two iodides are reversed, vaporous absorption following the order of liquid absorption. I have frequently encountered cases of this character. The simultaneous change of diathermic position of liquid and vapour indicates that the foreign ingredient, whatever it was, possessed approximately the same volatility as the substance which it vitiated.

[To be continued.]

\section{Notices respecting New Books.}

Kant's Critique of Pure Reason: translated into English by F. MAX MĩLler. 2 vols. London: Macmillan and Co.

'WHIS translation of Kant's great work appears in commemoration of the Centenary of its first publication. In the second volume we have the work proper, namely, a translation of the first edition; and in the first volume we have a preface by the trauslator, an Historical Introduction by Prof. Noiré, and a translation of the supplements which were added by Kant to the second edition.

In his preface the eminent translator states why he thought he might translate Kant's Critique, why he thonght he ought to do it, 